\title{
Enhancing Student Engagement and Self-Evaluation Using Student Response Systems
}

\author{
Siobhán Lucey \\ University College Cork
}

\author{
Brendan McElroy \\ University College Cork
}

Lauren McInally
University of Strathclyde

Briony Supple
University College Cork

Whilst previous studies are broadly in agreement on the effectiveness of student response systems (hereafter SRSs) in enhancing student engagement, there are gaps in the literature relating to study design and outcomes assessed. This study offers enhancements to study design. First, by collecting baseline data, engagement levels can be conditioned and changes in engagement attributable to the SRS detected. Second, it is one of the few studies that employs a comprehensive measure of student engagement. Third, analysis occurs at student level rather than class level. The study finds increased positive perceptions towards selfevaluation (both self and relative assessment) and ability to express opinion, in addition to strong student positivity towards the SRS.

Keywords: undergraduate economic courses, student response systems, self-evaluation, student engagement

\section{INTRODUCTION}

The prevalence of student response systems (hereafter SRS) in higher education has grown significantly in the last few decades. Student classroom participation and assessment of student performance particularly in larger classes (Ballantyne, Hughes and Mylonas, 2002), has often been regarded as problematic in pedagogical research (Black and Wiliam, 1998; Fies and Marshall, 2006; Beaumont, O'Doherty and Shannon, 2011). Growth in technology, coupled with popularity of handheld devices has, however, led to the development in SRS with the intention of increasing classroom participation and engaging students in the lecture setting (Denker, 2013). A number of studies identify benefits to students participating in the classroom using SRS including increased student involvement and attendance (Bullock et al., 2002; Greer and Heany, 2004), learning (Davies and Graff, 2005; Stowell and Nelson, 2007; Premkumar, 2016) and 
engagement (Denker, 2013; Denker, Manning, Heuett and Summers, 2018; Limniou and Mansfield, 2019). This research seeks to examine the effects of an SRS on student participation and engagement in large undergraduate economics modules at both an Irish and UK university during the academic year of 2018/19. We compare a control period (no SRS in place) with a trial period (SRS in place) by surveying students at the end of each period regarding their perceived levels of engagement.

\section{LITERATURE REVIEW}

Widening access to higher education has led to student enrolment significantly increasing which in turn has implications from a pedagogical perspective (Ryan, French and Kennedy, 2019). Constructivism asserts that student learning is enhanced using an active process, whereby knowledge is obtained through the interaction between lecturers and students (Van Daele, Frijns and Lievens, 2017). A prevalent challenge facing lecturers is the ability to engage students within a large classroom environment. Underpinning this notion is the idea that students believe that the chance to interact with the lecturer is minimal given the large class size (Salemi, 2009). Student engagement within lectures has been associated with increased retention of information, motivation and confidence in the subject area (Cavanagh, 2011) and improved academic self-efficacy (Bandura, 1997). It is therefore important for lecturers to recognize opportunities which can lead to enhanced student engagement (Gourlay, 2015).

However, 'engagement' as a concept is much contested. For the context of this paper, we see engagement as distinct from 'achievement' and grades. Furthermore, in order to protect anonymity, we have not pursued a line of inquiry which looks to correlate levels of engagement with grades.

A number of studies have examined the use of SRS in increasing student engagement. Although several studies find students enjoy using SRS and believe they benefit from them (Knight and Wood, 2005; Stowell and Nelson, 2007; Denker et al., 2018), studies are mixed in terms of whether SRS enhance learning and whether they ultimately translate into better grades for the student. Lundeberg et al. (2011) studied the effects of a clicker system across 11 institutions within the science discipline and highlighted that although students report enhanced understanding when exposed to a SRS environment, this did not increase performance for all individuals and was dependent on the topic covered.

Heaslip, Donovan and Cullen (2014) use an SRS in the form of handheld clickers to ascertain the impact these have on student engagement within a large classroom setting. A sample of 120 business students were asked to measure their opinion with respect to ten statements relating to interaction and participation within the lecture. The responses were measured on a 5-point Likert scale ranging from strongly disagreeing with the statements to strongly agreeing with the statements. The same questions were asked before, during and after the SRS was used to establish whether student engagement improved as a result of its introduction. Interviews were also conducted with a subsample of students to obtain qualitative data regarding using SRS in the class. The results indicate that students enjoyed using the SRS, particularly as their responses to the questions were anonymized, meaning that there were no consequences to answering incorrectly (Raes, Vanderhoven and Schellens, 2015).

Salemi (2009) used clickers within an economics course to assess the impact on student engagement. Students paid between $\$ 20$ to $\$ 30$ for their clickers and an additional registration fee of up to $\$ 15$ for each course that used clickers. Salemi (2009) reported that the use of clickers within a large classroom environment enhanced student engagement by encouraging them to participate from day one of the module and providing a signal to them that lecturers were interested in their views and performance. Van Daele et al. (2017) examined the impact of the use of handheld devices (smart phones, tablets etc.) within a large classroom environment. A benefit of handheld devices, over clickers, is that new devices do not have to be purchased, thus reducing the costs associated with this method as there are no direct costs for students and minimal costs for the institution. The study revealed that both students and lecturers reported an increased perception of involvement within the lecture. Moreover, students agreed that handheld devices should be used within the classroom to foster learning.

Self-assessment and the ability to self-evaluate mastery of course content relative to classmates (relative assessment) are important for formative assessment, in allowing students to develop an understanding of 
the level of their knowledge (Boud, Lawson and Thompson, 2013) and in fostering a sense of peer community (Petrovic and Pale, 2015; Wang, 2015), but difficulties arise in incorporating this within a large classroom environment. The introduction of SRS has facilitated self and relative assessment. Students can recognize their ability relative to their peers given the active learning nature of SRS (Hoekstra, 2008; Walker and Barwell, 2009). Self and relative assessment have been associated with improved personal responsibility, improved performance (Nulty, 2011) and the ability for students to recognize and address knowledge gaps (Topping, 1998). Moreover, the anonymity associated with SRS is beneficial in reducing the sense of peer pressure associated with relative assessment (Hoekstra, 2008; Raes et al., 2015). Despite the findings of some significant benefits associated with the use of SRS, potential challenges have been identified including the time dedicated to implementing the SRS (Kay and LeSage, 2009), the usefulness of the feedback received (Wang, 2015) and the effectiveness of SRS on older students (Licorish et al., 2018).

While existing literature provides insight into the effects of SRS on student engagement, a number of weaknesses can be identified. First, while student engagement is multi-dimensional, many studies use ad hoc measures. This study uses the comprehensive and validated measure developed in Heaslip et al. (2014), which conceptualizes 'engagement' as Interactivity, Self-Assessment, Relative Assessment, Personal Opinion, Involvement, Participation, Feedback, Engagement and Attentiveness. In particular selfevaluation has been identified as a gap in the literature. Second, many studies do not collect student attitudes from the period before SRS were implemented. This is necessary in order to establish the independent effect of the SRS. Third, as identified by Lundberg et al. (2011), the effect of SRS interventions varies across institutions, hence this study is conducted on Economics students in both an Irish and UK university. Finally, other quantitative studies aggregate student responses to the class average which loses valuable information on intra-class variation. Using a random effects ordered logit model, this study incorporates that information.

\section{DATA AND METHODOLOGY}

\section{Sample and Data}

The study involved cohorts of students from two universities. Specifically, the sample frame was undergraduate (first and second year) economics modules studied in two business schools which employ the same SRS in an Irish and UK university. The baseline sample consisted of 328 students, 192 students responded to the follow-up survey and, of those, 122 consented to participate in both the pre and post SRS surveys. The modules were reasonably homogenous consisting of males and females typically aged between 18 and 21.

Students in each location were exposed to the usual mechanisms for student engagement (such as the lecturer posing a few questions to the audience now and then to check for understanding and comprehension by the lecturers for the first half of the semester (approx. 6 weeks) and were then surveyed on their level of engagement. Questions were based on Heaslip et al's (2014) validated measure pertaining to engagement and included questions such as "I interact with the lecturer in class", I am involved in learning during class", I am engaged in class" etc. Students rated such questions on a 5-point Likert scale, ranging from 1 "Strongly disagree" to 5 "Strongly agree".

An SRS app 'Mentimeter' was introduced in the second half of the semester. This app allows students to anonymously give their opinions on questions in the form of multiple-choice questions, open-ended questions or scale questions. It does not require any voting devices or downloads. Students navigate to the Mentimeter website www.menti.com using their mobile devices (smartphone, laptop or tablet) where they input the 6-digit code given to them by the lecturer to access the questions. It allows lecturers to create presentations, mostly consisting of short multiple choice question sets, with real-time feedback and displays the results in several ways including tables, charts and word clouds.

Although it depended on the topic of the lecture, the typical approach used was to deliver a block of lecture material (typically 20 minutes), followed by a period of review and assimilation facilitated by the app in the form of multiple-choice questions relating to the material delivered. Mentimeter was employed 
for approximately 10-15 minutes in each of the lectures with students responding individually to the questions. For example, in a Principles of Economics module, an example of a MCQ asked:

\author{
Which of the following will cause the demand curve for a normal good to shift to the right? \\ a. A fall in the income levels of consumers. \\ b. An increase in the price of a complementary good. \\ c. An increase in the price of a substitute good. \\ d. An increase in the cost of the inputs used to produce the good.
}

At the end of the semester, students were surveyed again on their level of engagement. Students were sent a survey via Lime Survey/Qualtrics and were given an opportunity to complete it in the lecture or alternatively via Blackboard. For ethical reasons and to maintain students' anonymity, no student performance data was collected in either of the surveys

The study measured the level of engagement using a modified version of that reported in Heaslip et al. (2014), which is one of the few validated measures of classroom engagement in the literature. Concepts addressed were student involvement; student engagement in class; student participation in class; student feedback from lecturer and student self-assessment. All concepts were measured as degree of agreement with statements on a 5-point Likert scale. A number of other variables were also collected including the respondent's module and level of attendance. The respondent's module was collected to control for clustering at the module level. The number of lectures attended is used as a proxy measure for student interest in and application to the subject, both of which may affect overall engagement. The survey conducted in the second part of the semester was supplemented by a number of additional questions to assess students' feedback on feasibility issues such as web access and user-friendliness of the app itself.

\title{
Methodology
}

Using the standard assumption of a continuous latent response variable, previous literature typically tested for the difference in means using a t-test (Heaslip et al., 2014). This approach does not allow for clustering at the module level, nor for respondent heterogeneity. Since each student in this study is surveyed twice, the data form a natural 2-period panel structure. Thus, we specify an econometric model at the level of the student. Hence, in addition to t-tests, we also specify the following econometric model:

$y_{i t}=\beta x_{i t}+v_{i}+\varepsilon_{i t}$

where $y$ is the 5-category criterion being modelled, $x$ is the matrix of covariates (number of lectures attended, module) and $\beta$ is a vector of parameter estimates; $i$ is the respondent and $t$ is the period ( 0 for baseline, 1 for follow-up); $\mathrm{v}_{i}$ is unobservable time-invariant respondent heterogeneity, which is assumed to vary randomly, and $\varepsilon_{i t}$ is the idiosyncratic error term. Thus, the model accounts for both clustering of responses at the module level and respondent heterogeneity.

\section{FINDINGS}

Table 1 describes the average responses for each criterion pre- and post-introduction of the SRS at module level. 
TABLE 1

COMPARISON OF MEANS BY CRITERIA AT MODULE LEVEL

\begin{tabular}{|l|l|l|l|l|}
\hline Criterion & Abbrev. & Pre & Post & Sig \\
\hline I interact with the lecturer in class & Interactivity & 2.45 & 2.95 & $* * *$ \\
\hline I am involved in learning during class & Involvement & 3.58 & 3.77 & $*$ \\
\hline I am engaged in class & Engaged & 3.71 & 3.77 & \\
\hline I am attentive in class & Attentiveness & 3.73 & 3.82 & \\
\hline I participate in classroom discussion & Participate & 2.49 & 2.59 & \\
\hline $\begin{array}{l}\text { I provide my opinion to questions from the } \\
\text { lecturer during class }\end{array}$ & My opinion & 2.12 & 2.43 & $* * *$ \\
\hline $\begin{array}{l}\text { I receive feedback on my understanding of } \\
\text { lecture content in class }\end{array}$ & Feedback & 2.74 & 2.98 & $* *$ \\
\hline $\begin{array}{l}\text { I can assess whether I am following } \\
\text { lecture content during class }\end{array}$ & Self-assessment & 3.66 & 3.89 & \\
\hline $\begin{array}{l}\text { I can assess my understanding of lecture } \\
\text { content relative to other students during } \\
\text { class }\end{array}$ & Relative assessment & 3.28 & 3.60 & $* * *$ \\
\hline
\end{tabular}

Note: $* * *=1 \% ; * *=5 \%$ and $*=10 \%$ level of significance for the difference between the two means using a t-test.

Taking the variables that were significant at the 5\% level, the difference in module means between the pre- and post-introduction of the SRS was greatest for, in rank order, Interactivity at 0.5 , Relative Assessment at 0.32 , followed by My opinion, Self-Assessment, Feedback. Involvement was significant at the $10 \%$ level while the difference between pre- and post-surveys were not significantly different from zero for Engaged, Attentiveness and Participate.

As described in the methodology, the above t-tests do not allow for clustering of responses at the module level, so an individual level model was specified. The results of this random effects ordered logit model for all criteria are presented in Table 2. Rather than report the results of the full models (including control variables and model diagnostics) for each criterion, Table 2 focuses on the results of the effect of SRS for each criterion (the full model results for all criteria are available on request). The odds ratios are interpreted as the chances that a student's response will be one category higher than the reference group for any given variable, with greater than one indicating a higher chance and less than one indicating the opposite. The effect of using SRS was statistically significant in the case of 5 criteria, and statistically insignificant in the case of the other 4. A respondent was 2.7 times more likely to report a higher level of Interactivity with SRS than without. The odds ratios for Involvement, My opinion, Self-Assessment Relative Assessment were 1.67, 1.91, 2.55 and 2.36 respectively. All five were statistically significant at the $5 \%$ level. The remaining 4 criteria had lower odds ratio and were statistically insignificant. 
TABLE 2

ODDS RATIOS OF EFFECT OF SRS

\begin{tabular}{|l|c|}
\hline Criterion & Odds Ratio \\
\hline Interactivity & $2.70^{* *}$ \\
& $(1.25)$ \\
\hline Involvement & $1.67 * * *$ \\
& $(0.30)$ \\
\hline Engagement & 1.20 \\
& $(0.19)$ \\
\hline Attentiveness & 1.38 \\
& $(0.52)$ \\
\hline Participate & 1.33 \\
& $(0.28)$ \\
\hline My opinion & $1.91 * * *$ \\
& $(0.35)$ \\
\hline Feedback & 1.54 \\
& $(0.53)$ \\
\hline Self-Assessment & $2.55^{* * *}$ \\
& $(0.57)$ \\
\hline Relative Assessment & $2.36 * * *$ \\
& $(0.65)$ \\
\hline Note: Clustered robust standard errors in parenthesis; $* * *=1 \%, * *=5 \%$ and $*=10 \%$ level of significance respectively
\end{tabular}

The post-SRS questionnaire also contained supplementary questions to capture students' perceptions on using the SRS and the need for future implementation. An overview of the results can be found in Table 3. Most students had access to a relevant device (99\%) and answered the lecture questions via the SRS (98\%). The mean for the perceived ease of use of the app is 4.55 (out of 5) and the mean for the continued use of the SRS in future lectures is 4.39 (out of 5). Further, the students did not encounter any issues regarding access to the internet or the reliability of the app (mean of 4.38 out of 5). These relatively high means suggest that students were happy with the use of the app and would like to see it used again. It does appear though that they would like additional time to answer the questions via the app (mean of 3.91 out of 5) which is something the lecturers could reflect on in future lectures. All means were statistically significant.

TABLE 3

FEASIBILITY AND EASE OF USE OF SRS

\begin{tabular}{|l|l|l|}
\hline Question & Mean & Std. Error \\
\hline $\begin{array}{l}\text { I had a device (smartphone, tablet, laptop) at my disposal to } \\
\text { answer the SRS questions }\end{array}$ & 0.99 & 0.01 \\
\hline I answered the SRS questions & 0.98 & 0.01 \\
\hline I found the SRS app easy to use & $4.55^{* * *}$ & 0.07 \\
\hline Web access and app reliability were never a problem & $4.38^{* * *}$ & 0.09 \\
\hline I had sufficient time to answer questions posed on SRS & $3.91^{* * *}$ & 0.09 \\
\hline I think that apps like the SRS used should be used in all lectures & $4.39^{* * *}$ & 0.08 \\
\hline
\end{tabular}

Note: $* * *=1 \%, * *=5 \%$ and $*=10 \%$ level of significance respectively for the difference between the mean and the hypothesized value of 3 (neither agree nor disagree) using a t-test. 
In the post SRS survey, students were also given the opportunity to provide any additional suggestions or remarks. Comments from students pointed to some further interesting findings regarding the following themes:

Interactivity/My opinion/Involvement:

- 'I really enjoyed using it and found that if you're normally a shy student who doesn't like speaking up in class it was very beneficial.'

- 'I believe that using the app encourages class participation and a new and refreshing way of learning, the way that the lectures are split for attentive listening of the slideshows to using our devices for SRS is a very innovative and new way of learning. I highly suggest that this should be used in any course or lecture.'

Self-assessment:

- 'Using the app was an excellent method of assessing whether I understood the content of the lecture or if I did not.'

- 'The SRS really helps me with revision and to allows me to check my understanding.'

Feedback:

- 'I thought the app was a really good idea of getting feedback from students since the lectures are so big it's very unlikely a student would ask questions or respond to feedback, but the app really helps people have a say and I think it's good to see how people answered.'

The above elements are thematic areas of interest to the research team and will be investigated as part of future research.

\section{CONCLUSION}

The results indicate that students reacted positively to the SRS. All odds ratios for each criterion exceeded one, quite considerably so for some criteria. There were high effects of the app on Interactivity, Self-Assessment, Relative Assessment, My Opinion and Involvement compared to Participate, Feedback, Engaged and Attentiveness. Additionally, the first group of criteria are statistically significant, the second group are not.

Given the high effects of student interactivity and involvement, one would have thought that this would relate to higher effects on engagement and attentiveness. However, this was not the case. Perhaps the underlying concepts measured by these criteria were very similar, such that the engagement and attentiveness effects were captured by the interaction and involvement criteria.

The results relating to relative and self-assessment and opinion giving are particularly noteworthy and contribute to the existing SRS literature. This points to the strength in this study of using a comprehensive, multidimensional measure that included evaluation alongside other dimensions of engagement. Further this finding is important in providing evidence to support the idea that self and relative assessment are introduced from the onset of one's studies in higher education, something which has been found to be difficult to introduce within first year programmes (Brown, 2020), but nonetheless desirable given the benefits (Nulty, 2011). The finding regarding 'Opinion' suggests that SRS allows students to engage in critical thinking. These three results suggest that the app facilitated the quick development of formative feedback which is crucial to effective learning for students (Sadler, 1989, 1998; Black and William, 1998a, b; Beaumont et al., 2011). Such feedback should also hopefully enhance students' academic self-efficacy (Bandura, 1997), which would be particularly helpful for students with low self-efficacy who are unwilling to seek help in large classes (Ryan and Pintrich, 1997). This is a line of investigation we continue to follow.

Furthermore, there is significant pedagogical evidence favouring formative feedback as a means of improving student learning (Dawson et al, 2019; Dawson, Carless \& Lee, 2021; Hattie \& Timperley, 2007; Henderson et al., 2018; Winstone \& Boud, 2019). This often places an increased burden on lecturers to provide detailed feedback on student assignments, the opportunity cost of which is under-researched. By providing informal feedback in class in real-time, our findings on relative-assessment, self-assessment and opinion suggest that student-generated formative feedback is another effective pathway to improved 
learning, at presumably lower cost than the lecturer generated pathway. Whether student generated feedback of this type is a complement to or a substitute for lecturer generated feedback is an area for future research.

Whilst no information was collected from the lecturers involved, their general feedback was that notwithstanding the time and effort required to organize the questions etc., the use of the SRS was beneficial in obtaining immediate feedback on students' comprehension. Furthermore, they observed that the students did enjoy using it and where applicable the competitive nature of it.

Finally, the decision to adopt a technology depends on its costs as well as its benefits. This study reports that students and lecturers found it beneficial. With respect to costs, the explicit cost of the recommended plan for educational institutions is $\$ 24.99$ per month excluding tax (billed annual) per lecturer (Mentimeter.com, 2020). There is also the additional implicit cost which is the opportunity cost of the lecturer's time and resources. Whether the benefit exceeds the cost is a decision for university decisionmakers.

The study has some limitations. As we wished to maintain respondent anonymity, we were unable to relate findings to student grades. This is an area for future research. Longer term outcomes like student retention, engagement in class in subsequent years or in tutorials, student satisfaction with academic experience could also be considered. In order to determine the causal effect of the SRS, a randomised controlled trial or natural experiment would be required.

Despite these limitations, this study has found evidence that SRS enhanced student engagement and self-evaluation. It appears to be cost-effective, and, resource concerns notwithstanding, would enhance the quality of the learning and teaching experience. In light of the COVID-19 pandemic, where there has been a rapid switch to online and blended learning, and consequently negative effects on the student experience (Aucejo et al., 2020), SRS may offset some of the negative effects on student learning and offer timely and easily facilitated ways for students to interact and engage within a class.

\section{STATEMENT ON OPEN DATA, ETHICS AND CONFLICT OF INTEREST}

Data for this project are unavailable due to data protection and privacy concerns. Ethical approval was obtained for the research in both universities. All participants were adults who gave informed consent. In the information sheet provided to the students, the goal of the study was fully disclosed, they were informed that participation was completely voluntary and that they could withdraw at any time from the study.

The authors do not wish to declare any conflicts of interest.

\section{REFERENCES}

Aucejo, E.M., French, J., Araya, M.P.U., \& Zafar, B. (2020). The impact of COVID-19 on student experiences and expectations: Evidence from a survey. Journal of Public Economics, 191, 1-15.

Ballantyne, R., Hughes, K., \& Mylonas, A. (2002). Developing Procedures for Implementing Peer Assessment in Large Classes Using Action Research Process. Assessment \& Evaluation in Higher Education, 27(5), 427-441.

Bandura, A. (1997). Self-Efficacy: The Exercise of Control. New York: W.H. Freeman and Company.

Beaumont, C., O'Doherty, M., \& Shannon, L. (2011). Reconceptualising Assessment Feedback: A Key to Improving Student Learning? Studies in Higher Education, 36(6), 671-687.

Black, P., \& Wiliam, D. (1998). Inside the Black Box: Raising Standards through Classroom Assessment. The Phi Delta Kappan, 80(2), 139-148.

Boud, D., Lawson, R., \& Thompson, D.G. (2013). Does student engagement in self-assessment calibrate their judgement over time? Assessment \& Evaluation in Higher Education, 38(8), 941-956.

Brown, M. (2020). Seeing students at scale: How faculty in large lecture courses act upon learning analytics dashboard data. Teaching in Higher Education, 25(4), 384-400.

Bullock, D.W., LaBella, V.P., Clinghan, T., Ding, Z., Stewart, G., \& Thibado, P.M. (2002). Enhancing the Student-Instructor Interaction Frequency. The Physics Teacher, 40, 535-541. 
Carini, R.M., Kuh, G.D., \& Klein, S.P. (2006). Student Engagement and Student Learning: Testing the Linkages. Research in Higher Education, 47, 1-32.

Cavanagh, M. (2011). Student's Experiences of Active Engagement through Cooperative Learning Activities in Lectures. Active Learning in Higher Education, 12(1), 23-33.

Davies, J., \& Graff, M. (2005). Performance in E-Learning: Online Participation and Student Grades. British Journal of Educational Technology, 36, 657-663.

Dawson, P., Carless, D., \& Lee, P.P.W. (2021). Authentic feedback: Supporting learners to engage in disciplinary feedback practices. Assessment and Evaluation in Higher Education, 46(2), 286-296.

Dawson, P., Henderson, M., Mahoney, P., Phillips, M., Ryan, T., Boud, D., \& Molloy, E. (2019). What makes for effective feedback: Staff and student perspectives. Assessment and Evaluation in Higher Education, 44(1), 25-36.

Denker, K. (2013). Student Response Systems and Facilitating the Large Lecture Basic Communication Course: Assessing Engagement and Learning. Communication Teacher, 27(1), 50-69.

Denker, K.J., Manning, J., Heuett, K.B., \& Summers, M.E. (2018). Twitter in the Classroom: Modeling Online Communication Attitudes and Student Motivations to Connect. Computers in Human Behavior, 79, 1-8.

Fies, C., \& Marshall, J. (2006). Classroom Response Systems: A Review of the Literature. Journal of Science Education and Technology, 15(1), 101-109.

Ghosh, S., \& Renna, F. (2009). Using Electronic Response Systems in Economics Classes. The Journal of Economic Education, 40(4), 354-365.

Gourlay, L. (2015). 'Student Engagement' and the Tyranny of Participation. Teaching in Higher Education, 20(4), 402-411.

Greer, L., \& Heany, P.J. (2004). Real-Time Analysis of Student Comprehension: An Assessment of Electronic Student Response Technology in an Introductory Earth Science Course. Journal of Geoscience Education, 52(4), 345-351.

Hattie, J., \& Timperley, H. (2007). The Power of Feedback. Review of Educational Research, 77(1), 81112.

Heaslip, G., Donovan, P., \& Cullen, J. (2014). Student Response Systems and Learner Engagement in Large Classes. Active Learning in Higher Education, 15(1), 11-24.

Henderson, M., Boud, D., Molloy, E., Dawson P., Phillips, M., Ryan, T., \& Mahoney, P. (2018). Feedback for Learning: Closing the Assessment Loop - Final Report. Canberra: Australian Government Department of Education and Training.

Hoekstra, A. (2008). Vibrant Student Voices: Exploring Effects of the use of Clickers in Large College Courses. Learning, Media and Technology, 33(4), 329-341.

Kay, R.H., \& LeSage, A. (2009). Examining the Benefits and Challenges of using Audience Response Systems: A Review of the Literature. Computers \& Education, 53(3), 819-827.

Knight, J.K., \& Wood, W.B. (2005). Teaching More by Lecturing Less. Cell Biology Education, 4(4), 298-310.

Licorish, S.A., Owen, H.E., Daniel, B., \& George, J.L. (2018). Students' Perception of Kahoot!'s Influence on Teaching and Learning. Research in Practice and Technology Enhanced Learning, 13(9).

Limniou, M., \& Mansfield, R. (2019). (Game-Based) Student Response Systems Engage Students with Research-Teaching Nexus Activities and Support Their Skills Development. Creative Education, $10(1), 36-47$.

Lundeberg, M.A., Kang, H., Wolter, B., delMas, R., Armstrong, N., Borsari, B., . . Herreid, C.F. (2011). Context Matters: Increasing Understanding with Interactive Clicker Case Studies. Educational Technology Research and Development, 59(4), 645-671.

Nicol, D.J., \& Macfarlane-Dick, D. (2006). Formative assessment and self-regulated learning: A model and seven principles of good feedback practice. Studies in Higher Education, 31(2), 199-218.

Nulty, D.D. (2011). Peer and Self-Assessment in the First Year of University. Assessment \& Evaluation in Higher Education, 36(5), 493-507. 
Petrovic, J., \& Pale, P. (2015). Students' Perception of Live Lectures' Inherent Disadvantages. Teaching in Higher Education, 20(2), 143-157.

Premkumar, K. (2016). Use of Student Response Systems for Summative Assessments. Creative Education, 7(13), 1851-1860.

Raes, A., Vanderhoven, E., \& Schellens, T. (2015). Increasing Anonymity in Peer Assessment by using Classroom Response Technology within Face-to-Face Higher Education. Studies in Higher Education, 40(1), 178-193.

Ryan, A., \& Pintrich, P. (1997). Should I ask for help? The role of motivation and attitudes in adolescents' help seeking in math class. Journal of Educational Psychology, 89(2), 329-341.

Ryan, T., French, S., \& Kennedy, G. (2019). Beyond the Iron Triangle: Improving the Quality of Teaching and Learning at Scale. Studies in Higher Education, 46(7), 1383-1394.

Sadler, D.R. (1989). Formative Assessment and the Design of Instructional Systems. Instructional Science, 18, 119-144.

Salemi, M.K. (2009). Clickenomics: Using a Classroom Response System to Increase Student Engagement in a Large-Enrollment Principles of Economics Course. The Journal of Economic Education, 40(4), 385-404.

Stowell, J.R., \& Nelson, J.M. (2007). Benefits of Electronic Audience Response Systems on Student Participation, Learning, and Emotion. Teaching of Psychology, 34(4), 253-258.

Topping, K. (1998). Peer Assessment between Students in College and Universities. Review of Educational Research, 68(3), 249-276.

Van Daele, T., Frijns, C., \& Lievens J. (2017). How do students and lecturers experience the interactive use of handheld technology in large enrolment courses? British Journal of Educational Technology, 48(6), 1318-1329.

Walker, R., \& Barwell, G. (2009). Click or Clique? Using Educational Technology to Address Students' Anxieties About Peer Evaluation. International Journal for the Scholarship of Teaching and Learning, 3(1), 1-20.

Wang, A.I. (2015). The Wear Out Effect of a Game-Based Student Response System. Computers \& Education, 82, 217-227.

Winstone, N., \& Boud, D. (2019). Exploring cultures of feedback practice: The adoption of learningfocused feedback practices in the UK and Australia. Higher Education Research and Development, 38(2), 411-425. 